\title{
Relationship between sleep duration and clustering of metabolic syndrome diagnostic components
}

This article was published in the following Dove Press journal:

Diabetes, Metabolic Syndrome and Obesity: Targets and Therapy

I April 201 I

Number of times this article has been viewed

\author{
Sayuri Katano' \\ Yasuyuki Nakamura ${ }^{1,2}$ \\ Aki Nakamura' \\ Yoshitaka Murakami ${ }^{3}$ \\ Taichiro Tanaka ${ }^{4}$ \\ Toru Takebayashi ${ }^{5}$ \\ Akira Okayama ${ }^{6}$ \\ Katsuyuki Miura ${ }^{2}$ \\ Tomonori Okamura ${ }^{7}$ \\ Hirotsugu Ueshima ${ }^{2}$ \\ for HIPOP-OHP \\ Research Group \\ 'Cardiovascular Epidemiology, Kyoto \\ Women's University, Kyoto, Japan; \\ ${ }^{2}$ Department of Health Science, \\ Shiga University of Medical Science, \\ Otsu, Japan; ${ }^{3}$ Department of Medical \\ Statistics, Shiga University of Medical \\ Science, Otsu, Japan; ${ }^{4}$ Department \\ of Health Sciences, Interdisciplinary \\ Graduate School of Medicine and \\ Engineering, University of Yamanashi, \\ Chuo, Japan; ${ }^{5}$ Department of \\ Preventive Medicine and Public \\ Health, School of Medicine, \\ Keio University, Tokyo, Japan; \\ ${ }^{6}$ The First Institute of Health Service, \\ Japan Anti-Tuberculosis Association, \\ Tokyo, Japan; ${ }^{7}$ Department of \\ Preventive Cardiology, National \\ Cardiovascular Center, Suita, Japan
}

Correspondence: Yasuyuki Nakamura Kyoto Women's University,

35 Imakumano Kitahiyoshi-cho,

Higashiyama-ku, Kyoto 605-850I, Japan

Tel/Fax +8I 75 53। 2 I62

Email nakamury@kyoto-wu.ac.jp
Objective: To examine the relation between sleep duration and metabolic syndrome (MetS). Methods: We examined the baseline data from 4356 healthy workers (3556 men and 800 women) aged 19-69 years. The physical activity of each participant was classified according to the International Physical Activity Questionnaire (IPAQ). We defined four components of MetS diagnostic components in this study as follows: 1) high blood pressure (BP) systolic $\mathrm{BP}[\mathrm{SBP}] \geq 130 \mathrm{mmHg}$, or diastolic $\mathrm{BP}[\mathrm{DBP}] \geq 85 \mathrm{mmHg}$, or on medication; 2) dyslipidemia (high-density lipoprotein-cholesterol concentration $<40 \mathrm{mg} / \mathrm{dL}$, or triglycerides concentration $\geq 150 \mathrm{mg} / \mathrm{dL}$, or on medication; 3 ) impaired glucose tolerance (fasting blood sugar concentration $\geq 110 \mathrm{mg} / \mathrm{dL}$, or if less than 8 hours after meals $\geq 140 \mathrm{mg} / \mathrm{dL}$ ), or on medication; and 4) overweight (body mass index $[\mathrm{BMI}] \geq 25 \mathrm{~kg} / \mathrm{m}^{2}$ ), or obesity (BMI $\geq 30 \mathrm{~kg} / \mathrm{m}^{2}$ ). There were 680 participants in the group, with sleep duration $<6$ hours $(15.6 \%)$.

Results: Those who had 0-4 MetS diagnostic components, including overweight, accounted for 2159, 1222, 674, 255, and 46 participants, respectively, in the Poisson distribution. Poisson regression analysis revealed that independent factors that contributed to the number of MetS diagnostic components were being male (regression coefficient $\mathrm{b}=0.752, P<0.001$ ), age ( $\mathrm{b}=0.026, P<0.001)$, IPAQ classification $(\mathrm{b}=-0.238, P=0.034)$, and alcohol intake ( $\mathrm{mL} /$ day $)$ ( $\mathrm{b}=0.018, P<0.001$ ). Short sleep duration ( $<6$ hours) was also related to the number of MetS $(b=0.162, P<0.001)$. The results of analyses with obesity component showed a similar association.

Conclusion: Short sleep duration was positively associated with the number of MetS diagnostic components independent of other lifestyle habits.

Keywords: short sleep duration, MetS diagnostic components, obesity

\section{Introduction}

The components of metabolic syndrome (MetS) diagnostic criteria, including high blood pressure (BP), dyslipidemia, impaired glucose tolerance (IGT), and obesity are thought to be related to daily lifestyle habits, including alcohol drinking, smoking, and physical activity. ${ }^{1-4}$ It has also been reported that both a decrease and an increase in sleep duration were associated with an increase in cardiovascular and noncardiovascular mortality. ${ }^{5,6} \mathrm{U}$-shaped associations were observed between sleep $(<5,5,6,7, \geq 8$ hours $)$ and MetS. $^{7}$

Numerous studies have shown that separate components of MetS are associated with a higher risk of coronary heart disease and stroke, and that a rise in the number of MetS components increases the incidence of cardiovascular disease (CVD) events following myocardial infarction. ${ }^{8-10}$ Thus, preventing development of each component of MetS 
using diagnostic criteria is more important than dichotomizing people into two groups, with and without MetS.

In the present study we comprehensively examined crosssectionally the relation between sleep duration and other lifestyle habits including physical activity, smoking, alcohol intake, and the number of MetS diagnostic components in a large sample of healthy workers in Japan.

\section{Methods}

\section{Participants}

We analyzed baseline data from the High-Risk and Population Strategy for Occupational Health Promotion (HIPOP-OHP) Study. ${ }^{11-14}$ In brief, HIPOP-OHP was an interventional survey to establish a methodology for reducing CVD risk factors at the workplace. This study population consisted of full-time workers at 12 large-scale companies throughout Japan. Each company had 500-1000 employees. Researchers followed data on CVD risk factors, lifestyle habits and consciousness about health, based on nutrition, physical activity, and smoking for 4 years. ${ }^{11-14}$ This study was performed as part of the management of safety and health with the approval of the Safety Hygiene Committee at each company. Accordingly, all employees were enrolled in this study. However, participation was voluntary, and we explained there was no need for participants to answer the required questionnaire if they did not want to. Approval for the study was obtained from the Institutional Review Board of Shiga University of Medical Science for ethical issues (No. 10-16). From 1999-2000, baseline data were collected from 7346 male and female workers aged from 19 to 69 years old.

The present study examined baseline data from 4356 participants (3556 men and 800 women) ages 19-69 years (mean \pm standard deviation: $41.3 \pm 9.6$ years) who underwent physical examination, a lifestyle survey, and blood chemical examination.

\section{Data collection and standardization}

Physical and laboratory data were standardized according to the manual of the HIPOP-OHP research group. ${ }^{11}$ Briefly, after 5 minutes of silent rest measured by a sandglass, blood pressure was measured twice for each participant using an automatic sphygmomanometer (Nihon Colin, BP-103iII) at each company, and the mean value was recorded. To measure the lipid concentrations in each participant, the company established a contract with a clinical laboratory; the blood testing was standardized through the US Cholesterol Reference Method Laboratory Network (CRMLN). ${ }^{15}$ The body mass index (BMI) was calculated as weight $(\mathrm{kg})$ divided by height squared $\left(\mathrm{m}^{2}\right)$.
Participants were asked about the type of, and time spent on, physical activities in their spare time for recreation, exercise, or sport in the previous month. The physical activity of each participant was converted into metabolic equivalent task (MET)-minutes per week (=MET level $\times$ minutes of activity/day $\times$ days per week) according to IPAQ, ${ }^{16}$ and participants were classified into four classes of physical activity as: class 1 , sedentary ( $<600$ MET-minutes per week); class 2, some activity ( $<1500$ but $\geq 600$ MET-minutes per week); class 3 , moderate activity ( $<3000$ but $\geq 1500$ MET-minutes per week); or class 4 , high ( $\geq 3000$ MET-minutes per week). Drinking habits for each subject were assessed by a questionnaire common to all companies. ${ }^{12}$ The frequency of alcohol intake during a typical week and the total alcohol intake on each occasion were determined and used to calculate the alcohol intake per week. This value was then divided by 7 to obtain the average alcohol intake per day. Subjects were asked to estimate their alcohol intake based on gou, a traditional Japanese drinking unit corresponding to $23 \mathrm{~g}$ of ethanol. One gou is equivalent to 2 US and UK drink units, or $180 \mathrm{~mL}$ of sake, and its ethanol content is roughly equivalent to that of a bottle of beer $(663 \mathrm{~mL})$, two single shots of whiskey $(70 \mathrm{~mL})$, a half glass of shochu $(110 \mathrm{~mL})$, or $240 \mathrm{~mL}$ of wine. Drinkers were defined as those consuming more than 0.3 gou ( 0.6 drinks) per week ( $1 \mathrm{~g}$ of ethanol a day).

Sleep duration was investigated by the question, "How many hours of sleep do you get on an average weekday per night?" in the lifestyle survey. Sleep duration of participants was categorized in four groups: $<6$ hours, 6 to $<7$ hours, 7 to $<8$ hours, and $\geq 8$ hours, with reference to a precedent study. $^{7}$

We defined four components for MetS in this study according to previous studies ${ }^{3,17,18}$ as follows: 1) high BP, $\mathrm{SBP} \geq 130 \mathrm{mmHg}$, or DBP $\geq 85 \mathrm{mmHg}$, or the use of an antihypertensive drug; 2) dyslipidemia, either serum high-density lipoprotein (HDL) cholesterol concentration $<40 \mathrm{mg} / \mathrm{dL}$, or serum triglycerides (TG) concentration $\geq 150 \mathrm{mg} / \mathrm{dL}$, or on medication for dyslipidemia; 3) IGT, fasting blood glucose concentration $\geq 110 \mathrm{mg} / \mathrm{dL}$, or if less than 8 hours after meals $\geq 140 \mathrm{mg} / \mathrm{dL}$ ), or on medication for diabetes mellitus; and 4) overweight, BMI $\geq 25 \mathrm{~kg} / \mathrm{m}^{2}$, or obesity, $\mathrm{BMI} \geq 30 \mathrm{~kg} / \mathrm{m}^{2}$.

\section{Statistical analyses}

The chi-square statistical test for nominal variables and one way analysis of variance for continuous variables were performed to assess whether there were significant differences among the groups stratified by sleep duration. 
Associations between the number of MetS diagnostic components, including overweight component, and sleep duration categories, taking a sleep duration of 6-7 hours as a reference, were analyzed by Poisson regression models. Model 1 included sex and age as covariates. Model 2 included model 1 covariates + IPAQ classification, smoking (non-, past, or current smoker; nonsmoker serves as reference), alcohol intake ( $\mathrm{mL} /$ day), and interaction terms (IPAQ $\times$ male, alcohol intake $\times$ male, current smoking $\times$ male). The above analyses were repeated after overweight component was replaced by obesity component. The associations between high BP, dyslipidemia, IGT, overweight, obesity, and sleep duration categories were analyzed by logistic regression models, adjusted for sex, age, IPAQ classification, smoking (non-, past, or current smoker; nonsmoker serves as reference), alcohol intake, and interaction terms (IPAQ $\times$ male, alcohol intake $\times$ male, current smoking $\times$ male) as covariates. All $P$ values were two-sided, and $P<0.05$ was considered significant. All analyses were performed using SPSS v15 (Chicago, IL, USA).

\section{Results}

Among the 4356 participants (3556 men and 800 women), $680(15.6 \%)$ were in the group of sleep duration $<6$ hours, 1779 in the group of sleep duration 6 to $<7$ hours $(40.8 \%), 1488$ in the group of sleep duration 7 to $<8$ hours $(34.2 \%)$, and 409 in the group of sleep duration $>8$ hours $(9.4 \%)$. There were 974 overweight (BMI $\geq 25 \mathrm{~kg} / \mathrm{m}^{2}$ ) participants $(22.4 \%)$, and 116 participants $(2.7 \%)$ with obesity $\left(\mathrm{BMI} \geq 30 \mathrm{~kg} / \mathrm{m}^{2}\right)$. Those who had $0-4$ MetS diagnostic components, including overweight component, accounted for 2159, 1222, 674, 255, and 46 persons, respectively, in the Poisson distribution. Characteristics of participants by group according to sleep duration are shown in Table 1. The mean SBP, DBP, alcohol intake, and percentage of current smokers were higher among the groups with a longer sleep duration. The mean BMI and percentage of obesity were lower among the groups with a longer sleep duration.

The results of Poisson regression analysis are shown in Table 2. The shortest sleep duration category contributed significantly to the number of MetS components in both models. Independent factors that contributed to the number of MetS diagnostic components were being male (regression coefficient $\mathrm{b}=0.639, P<0.001$ ), age ( $\mathrm{b}=0.026, P<0.001),<6$ hours of sleep duration ( $b=0.141, P<0.001)$ in model 1 . In model 2 , factors significantly contributing to the number of MetS components were being male $(b=0.752, P<0.001)$, age $(b=0.026$, $P<0.001)$, IPAQ classification ( $\mathrm{b}=-0.238, P=0.034)$, alcohol intake (mL/day) $(\mathrm{b}=0.018, P<0.001)$, and $<6$ hours of sleep duration $(\mathrm{b}=0.162, P<0.001)$. The interaction term (alcohol intake $\times$ male) contributed significantly to the number of MetS components $(\mathrm{b}=-0.017, P<0.001)$. The contribution of current smoking $(\mathrm{b}=-0.115, P=0.559)$ was not statistically significant. Although there were very few participants with obesity, the analyses repeated after overweight component was replaced by obesity component showed a similar association between short sleep duration and the number of MetS components.

The results of logistic regression analysis on associations between individual components of MetS and sleep duration adjusted for other lifestyle habits are shown in Table 3. For high $\mathrm{BP}$, being male (odds ratio $[\mathrm{OR}]=2.68$, 95\% confidence intervals $=[1.58-4.52] P<0.001)$, age $(\mathrm{OR}=1.05$ [1.04-1.06], $P<0.001$ ), and IPAQ (OR $=0.65$ [0.42-0.99], $P=0.044)$ contributed significantly. Sleep duration categories did not contribute to high BP. For dyslipidemia, being male $(\mathrm{OR}=3.70$ [2.02-6.74], $P<0.001)$, age $(\mathrm{OR}=1.03$ [1.02-1.03], $P<0.001)$, sleep $<6$ hours $(\mathrm{OR}=1.27$ [1.03-1.56], $P=0.023$ ), and IPAQ (OR = 0.60 [0.37-0.98], $P=0.040)$ contributed significantly. For IGT, age $(\mathrm{OR}=1.09$ [1.08-1.12], $P<0.001),<6$ hours sleep (OR $=1.49$ [1.03-2.15], $P=0.037)$ contributed significantly. For overweight, being male $(\mathrm{OR}=1.72[1.01-2.95], P<0.001)$, age $(\mathrm{OR}=1.02[1.01-1.02], P=0.048),<6$ hours sleep $(\mathrm{OR}=1.31$ [1.06-1.61], $P=0.011)$, and 7 to $<8$ hours of sleep duration $(\mathrm{OR}=0.79[0.66-0.94], P=0.010)$ contributed significantly. For obesity, age $(\mathrm{OR}=0.95$ [0.93-0.97], $P<0.001)$, and $<6$ hours sleep (OR $=1.90$ [1.18-3.05], $P=0.008)$ contributed significantly. Thus, for 3 out of 4 MetS diagnostic components, $<6$ hours sleep contributed positively. For overweight, 7 to $<8$ hours of sleep duration inversely contributed significantly.

\section{Discussion}

In the present study, we found a significant positive association between short sleep duration ( $<6$ hours compared with 6-7 hours sleep duration) and the number of MetS diagnostic components, regardless of BMI cutoff point was taken either $\geq 25 \mathrm{~kg} / \mathrm{m}^{2}$, or $\geq 30 \mathrm{~kg} / \mathrm{m}^{2}$. Most previous studies showed an association between short sleep duration and the risk of MetS, and some studies also showed that a longer sleep duration was associated with the risk of MetS. Santos et al studied 2164 Portuguese men and women, and found an association between a decrease in physical activity, an 
Table I Characteristics of participants by group according to sleep duration - HIPOP-OHP study

\begin{tabular}{|c|c|c|c|c|c|c|}
\hline & \multicolumn{6}{|c|}{ Sleep duration $^{\mathrm{a}}$} \\
\hline & $<6$ hours & 6 to $<7$ hours & 7 to $<8$ hours & $>8$ hours & Total & $P$ value \\
\hline Person N & 680 & 1779 & 1488 & 409 & 4356 & \\
\hline Age (years) & $40.4 \pm 9.5$ & $41.4 \pm 9.4$ & $41.4 \pm 9.6$ & $42.4 \pm 10.0$ & $41.3 \pm 9.6$ & 0.010 \\
\hline Female (\%) & 22.1 & 21.8 & 14.7 & 10.8 & 18.4 & $<0.001$ \\
\hline SBP (mmHg) & $117 \pm 17$ & $117 \pm 17$ & $119 \pm 17$ & $121 \pm 16$ & $118 \pm 17$ & 0.003 \\
\hline $\mathrm{DBP}(\mathrm{mmHg})$ & $72 \pm 12$ & $72 \pm 12$ & $73 \pm 12$ & $75 \pm 12$ & $73 \pm 12$ & $<0.001$ \\
\hline High BP (\%) & 24.3 & 24.1 & 25.8 & 28.4 & 25.1 & 0.275 \\
\hline Dyslipidemia (\%) & 29.6 & 25.9 & 26.3 & 28.4 & 26.8 & 0.251 \\
\hline IGT (\%) & 7.5 & 6.0 & 6.3 & 7.3 & 6.5 & 0.501 \\
\hline BMI $\left(\mathrm{kg} / \mathrm{m}^{2}\right)$ & $23.3 \pm 3.5$ & $23.0 \pm 3.2$ & $22.8 \pm 3.0$ & $22.8 \pm 3.0$ & $23.0 \pm 3.2$ & 0.004 \\
\hline $\mathrm{BMI} \geq 25 \mathrm{~kg} / \mathrm{m}^{2}$ (\%) & 27.2 & 23.1 & 19.5 & 21.8 & 22.4 & $<0.001$ \\
\hline $\mathrm{BMI} \geq 30 \mathrm{~kg} / \mathrm{m}^{2}(\%)$ & 4.7 & 2.5 & 2.3 & 1.5 & 2.7 & 0.003 \\
\hline IPAQ & $1.3 \pm 0.6$ & $1.3 \pm 0.6$ & $1.4 \pm 0.7$ & $1.3 \pm 0.7$ & $1.3 \pm 0.6$ & 0.005 \\
\hline Current smoking (\%) & 42.9 & 44.9 & 47.8 & 57.5 & 46.7 & $<0.001$ \\
\hline Alcohol intake $(\mathrm{mL} /$ day $)$ & $17.9 \pm 32.6$ & $17.6 \pm 27.9$ & $20.9 \pm 29.7$ & $27.7 \pm 39.9$ & $19.7 \pm 30.7$ & $<0.001$ \\
\hline MetS No $A^{b}$ & $0.88 \pm 0.99$ & $0.79 \pm 0.97$ & $0.78 \pm 0.95$ & $0.86 \pm 1.00$ & $0.81 \pm 0.97$ & 0.064 \\
\hline MetS No Bc & $0.66 \pm 0.82$ & $0.58 \pm 0.79$ & $0.61 \pm 0.78$ & $0.66 \pm 0.82$ & $0.61 \pm 0.79$ & 0.116 \\
\hline
\end{tabular}

Notes: The chi-square statistical test for nominal variables and one way analysis of variance for continuous variables were performed to assess whether there were significant differences among the groups stratified by sleep duration. We defined four components for MetS in this study as follows: I) High BP, SBP $\geq 130$ mmHg, or DBP $\geq 85 \mathrm{mmHg}$, or the use of an antihypertensive drug; 2) dyslipidemia, $\mathrm{HDL}<40 \mathrm{mg} / \mathrm{dL}$, or TG $\geq 150 \mathrm{mg} / \mathrm{dL}$, or on medication for dyslipidemia; 3 ) IGT, fasting blood sugar concentration $\geq 110 \mathrm{mg} / \mathrm{dL}$, or if less than 8 hours after meals $\geq 140 \mathrm{mg} / \mathrm{dL}$ ), or on medication for diabetes mellitus; 4 ) overweight, defined as BMI $\geq 25 \mathrm{~kg} / \mathrm{m}^{2}$, or obesity, defined as BMI $\geq 30 \mathrm{~kg} / \mathrm{m}^{2}$. aSleep duration = average sleeping hours per night on weekdays. ${ }^{b}$ MetS No A = number of MetS component including overweight component. 'MetS No B = number of MetS component including obesity component.

Abbreviations: BP, blood pressure; SBP, systolic blood pressure; DBP, diastolic blood pressure; IGT, impaired glucose tolerance; BMI, body mass index; IPAQ, International Physical Activity Questionnaire classification; MetS, metabolic syndrome; HDL, high-density lipoprotein; TG, triglycerides; IGT, impaired glucose tolerance.

increase in sleeping hours, and the risk of MetS. ${ }^{19}$ Hall et al studied self-reported sleep duration associated with MetS in a cross-sectional community-based cohort and found that both short ( $<7$ hours per night) and long ( $\geq 8$ hours per night) sleep duration were significantly correlated with MetS in middle-aged adults. ${ }^{7}$ On the other hand, in a study by Choi et al with 4222 Korean participants, short and long sleep duration were related to increased risk of MetS, while subjects with sleep duration of 7 hours demonstrated the lowest prevalence of MetS. ${ }^{20}$

Because obesity results in development of MetS diagnostic components, the most likely reason for the association

Table 2 Independent factors that contributed to the number of metabolic syndrome diagnostic components and sleep duration and lifestyle habits - results of Poisson regression analysis

\begin{tabular}{|c|c|c|c|c|c|c|c|c|}
\hline \multirow[t]{3}{*}{ Variable } & \multicolumn{4}{|c|}{ Overweight } & \multicolumn{4}{|c|}{ Obesity } \\
\hline & \multicolumn{2}{|c|}{ Model I ${ }^{a}$} & \multicolumn{2}{|c|}{ Model $2^{b}$} & \multicolumn{2}{|c|}{ Model Ia } & \multicolumn{2}{|c|}{ Model $2^{b}$} \\
\hline & $\beta^{c}$ & $P$ value & $\beta^{c}$ & $P$ value & $\beta^{c}$ & $P$ value & $\beta^{c}$ & $P$ value \\
\hline Male gender & 0.639 & $<0.001$ & 0.752 & $<0.001$ & 0.670 & $<0.001$ & -0.154 & 0.805 \\
\hline Age (year) & 0.026 & $<0.001$ & 0.026 & $<0.001$ & 0.028 & $<0.001$ & -0.049 & $<0.001$ \\
\hline Sleep group $<6$ hours $(680)$ & 0.141 & $<0.001$ & 0.162 & $<0.001$ & 0.152 & 0.007 & 0.641 & 0.008 \\
\hline 6 to $<7$ hours $(1779)$ & Ref & & Ref & & Ref & & Ref & \\
\hline 7 to $<8$ hours $(1488)$ & -0.057 & 0.152 & -0.045 & 0.270 & -0.007 & 0.878 & -0.032 & 0.893 \\
\hline$\geq 8$ hours (409) & -0.006 & 0.920 & -0.050 & 0.435 & 0.020 & 0.769 & -0.328 & 0.460 \\
\hline IPAQ & & & -0.238 & 0.034 & & & -0.351 & 0.547 \\
\hline Current smoking & & & -0.115 & 0.559 & & & -0.588 & 0.459 \\
\hline Alcohol intake $(\mathrm{mL} /$ day $)$ & & & 0.018 & $<0.001$ & & & 0.041 & 0.307 \\
\hline IPAQ $\times$ male & & & 0.176 & 0.078 & & & 0.119 & 0.804 \\
\hline Alcohol intake $\times$ male & & & -0.017 & $<0.001$ & & & -0.045 & 0.258 \\
\hline Smoking $\times$ male & & & 0.158 & 0.382 & & & 0.271 & 0.689 \\
\hline
\end{tabular}

Notes: Results of analysis by Poisson regression models on associations between the number of MetS diagnostic components (including overweight or obesity component)

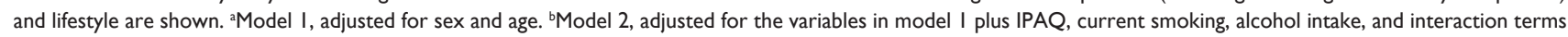
(IPAQ $\times$ male, alcohol intake $\times$ male, current smoking $\times$ male). ${ }^{c} \beta=$ regression coefficient.

Abbreviations: IPAQ, International Physical Activity Questionnaire classification; MetS, metabolic syndrome. 
Table 3 Independent factors that contributed to high BP, dyslipidemia, IGT, overweight, obesity and sleep duration including other lifestyle habits - results of logistic regression analysis

\begin{tabular}{|c|c|c|c|c|c|c|c|c|c|c|}
\hline \multirow[t]{2}{*}{ Variable } & \multicolumn{2}{|c|}{$\begin{array}{l}\text { High BP } \\
(\mathrm{N}=1094)\end{array}$} & \multicolumn{2}{|c|}{$\begin{array}{l}\text { Dyslipidemia } \\
(N=1 / 69)\end{array}$} & \multicolumn{2}{|c|}{$\begin{array}{l}\text { IGT } \\
(N=282)\end{array}$} & \multicolumn{2}{|c|}{$\begin{array}{l}\text { Overweight } \\
(N=974)\end{array}$} & \multicolumn{2}{|c|}{$\begin{array}{l}\text { Obesity } \\
(N=116)\end{array}$} \\
\hline & OR & $95 \% \mathrm{Cl}$ & $\overline{O R}$ & $95 \% \mathrm{Cl}$ & $\overline{\text { OR }}$ & $95 \% \mathrm{Cl}$ & OR & $95 \% \mathrm{Cl}$ & OR & $95 \% \mathrm{Cl}$ \\
\hline Male gender & $2.68^{\mathrm{a}}$ & I.58-4.52 & $3.70^{\mathrm{a}}$ & $2.02-6.74$ & 1.96 & $0.39-9.77$ & $1.72^{\mathrm{a}}$ & $1.01-2.95$ & 0.86 & $0.25-2.92$ \\
\hline Age & $1.05^{\mathrm{a}}$ & $1.04-1.06$ & $1.03^{\mathrm{a}}$ & $1.02-1.03$ & $1.09^{a}$ & $1.08-1.12$ & $1.02^{b}$ & $1.01-1.02$ & $0.95^{\mathrm{a}}$ & $0.93-0.97$ \\
\hline $\begin{array}{l}\text { Sleep }<6 \text { hours } \\
(594)\end{array}$ & 1.09 & $0.88-1.36$ & $1.27^{\mathrm{b}}$ & $1.03-1.56$ & $1.49^{\circ}$ & $1.03-2.15$ & $1.3 \mathrm{I}^{\mathrm{b}}$ & $1.06-1.61$ & $1.90^{\mathrm{a}}$ & I.18-3.05 \\
\hline $\begin{array}{l}6 \text { to }<7 \text { hours } \\
\text { (1557) }\end{array}$ & Ref & & Ref & & Ref & & Ref & & Ref & \\
\hline $\begin{array}{l}7 \text { to }<8 \text { hours } \\
(1297)\end{array}$ & 1.06 & $0.90-1.26$ & 0.96 & $0.82-1.14$ & 1.01 & $0.74-1.37$ & $0.79^{\mathrm{b}}$ & $0.66-0.94$ & 0.97 & $0.6 I-1.54$ \\
\hline$\geq 8$ hours ( 344 ) & 1.01 & $0.76-1.31$ & 0.97 & $0.75-1.25$ & 0.95 & $0.59-1.50$ & 0.83 & $0.63-1.09$ & 0.72 & $0.30-1.72$ \\
\hline IPAQ & $0.65^{\mathrm{b}}$ & $0.42-0.99$ & $0.60^{\mathrm{b}}$ & $0.37-0.98$ & 1.76 & $0.45-6.91$ & 0.89 & $0.58-1.37$ & 0.70 & $0.23-2.21$ \\
\hline Current smoking & 0.64 & $0.30-1.39$ & 1.22 & $0.54-2.73$ & 1.02 & $0.12-8.95$ & 0.82 & $0.39-1.72$ & 0.56 & $0.12-2.63$ \\
\hline Alcohol intake & 1.02 & $0.99-1.04$ & 1.02 & $0.99-1.05$ & 1.04 & $0.95-1.14$ & 1.03 & $1.00-1.05$ & 1.04 & $0.96-1.13$ \\
\hline IPAQ × male & $\mathrm{I} .4 \mathrm{I}$ & $0.98-2.03$ & 1.34 & $0.86-2.05$ & 0.60 & $0.16-2.25$ & 1.14 & $0.78-1.67$ & 1.12 & $0.44-2.87$ \\
\hline Alcohol $\times$ male & 0.99 & $0.97-1.01$ & 0.98 & $0.95-1.01$ & 0.96 & $0.88-1.05$ & $0.97^{b}$ & $0.95-0.99$ & 0.96 & $0.88-1.03$ \\
\hline Smoking $\times$ male & 1.35 & $0.67-2.70$ & 1.06 & $0.50-2.22$ & 0.98 & $0.12-7.92$ & 1.29 & $0.67-2.51$ & 1.31 & $0.35-4.93$ \\
\hline
\end{tabular}

Notes: ORs and $95 \% \mathrm{Cls}$ of analyses by logistic regression models on associations between high $\mathrm{BP}$, dyslipidemia, IGT, overweight (BMI $\left.\geq 25 \mathrm{~kg} / \mathrm{m}^{2}\right)$, obesity $\left(\mathrm{BMI} \geq 30 \mathrm{~kg} / \mathrm{m}^{2}\right)$ and sleep duration including other lifestyle habits and interaction terms (IPAQ $\times$ male, alcohol intake $\times$ male, current smoking $\times$ male) are shown. All covariates included are shown in this Table. ${ }^{\mathrm{a}} \mathrm{P}<0.0 \mathrm{I}{ }^{\mathrm{b}} \mathrm{P}<0.05$.

Abbreviations: OR, odds ratio; Cl, confidence interval; BP, blood pressure; IGT, impaired glucose tolerance; BMI, body mass index; IPAQ, International Physical Activity Questionnaire classification.

between short sleep duration and MetS may come from the association between short sleep duration and obesity. We also found significant positive associations between sleep duration $<6$ hours and obesity. Furthermore, sleep duration 7-8 hours was associated with the lowest risk of obesity in our study. Previous studies indicated a clear association between short sleep duration and elevated BMI and obesity, ${ }^{21-23}$ reduced leptin, and elevated ghrelin. ${ }^{24,25}$ One mechanism by which short duration sleep may predispose to weight gain is by increasing caloric intake. Partial sleep deprivation experiments in humans caused hyperphagia. Comparing 4 hours of sleep per night to 10 hours over a period of 2 days, both hunger and appetite scores on a visual analog scale were elevated by sleep deprivation. ${ }^{25}$ In a situation where food is readily available, sleep deprivation may simply represent an increased opportunity to eat, especially if most of the waking-time is spent in sedentary activities such as watching television. ${ }^{26}$ In the epidemiologic literature, those studies that attempted to quantify caloric intake found no relationship between sleep duration and dietary consumption. ${ }^{27-30}$ However, two epidemiologic studies demonstrated that short sleepers have reduced levels of leptin and elevated levels of ghrelin, supporting an effect of short sleep durations on appetite regulation. ${ }^{24,31} \mathrm{Chronic}$ partial sleep deprivation also clearly leads to feelings of fatigue, and this tiredness may lead to reductions in physical activity. In the Nurses' Health Study and Nurses' Health
Study 2, short sleep durations were associated with reduced reported physical activity. ${ }^{27,32}$

In the present study, short sleep duration was associated with the risk of IGT. Previous cross-sectional studies indicated that short and long sleep duration were associated with an increased risk of developing IGT or diabetes mellitus, independent of confounding factors. ${ }^{33-35}$

We also found an association between dyslipidemia and shorter sleep duration, and several studies have shown this association. In a study by van den Berg et al, people who slept longer and spent more time in bed had a higher total/HDL cholesterol ratio among 768 participants of the Rotterdam Study. ${ }^{36}$ In another study by Kaneita et al, both short and long sleep duration were associated with a high serum TG level or a low HDL cholesterol level, whereas compared with men sleeping 6-7 hours, the risk of a high low-density lipoprotein (LDL) cholesterol level was lower among men with sleeping duration $\geq 8$ hours. ${ }^{37}$

We found no association between high BP and sleep duration. Additional analysis between short duration sleep and hypertension (defined as SBP $\geq 140$, or DBP $\geq 90 \mathrm{mmHg}$, or on anti-hypertensive medication) yielded similar results (data not shown). However, several studies showed an association between short sleep duration and hypertension. In a study in a cohort of 10,308 British civil servants aged 35-55 years, short sleep duration ( $\leq 5$ hours per night) was associated with a higher risk of hypertension compared with a group sleeping 
7 hours among women (but no association detected in men). ${ }^{38}$ Gangwisch et al studied 4810 participants, and found that sleep duration of $\leq 5$ hours per night was associated with a significantly increased risk of hypertension. ${ }^{39}$ We have no possible explanations for the lack of association between high BP and short sleep duration in our study.

The strengths of our study include being populationbased, large-scale, and multi-site, with highly standardized methods. Since the study included men and women of a broad range of ages, the findings are likely to be generalizable to middle-aged Japanese. However, our study has some limitations. First, this study was limited by its cross-sectional design. Thus, the causal implications of short sleep duration for MetS should be taken cautiously. Second, we did not measure waist circumference (WC). However, we showed in a population-based study that BMI and WC correlated very well in men and women, and that BMI could be used instead of WC in a study when the latter was not available. ${ }^{40}$ Third, although we did not have data on food intake and sleep apnea, these may make important contributions to MetS.

In conclusion, our results indicated that shorter sleep duration ( $<6$ hours of sleep duration per night) was associated with an increased number of MetS diagnostic components, and 7 to $<8$ hours of sleep duration was associated with the lowest risk of obesity.

\section{Acknowledgments}

This study was funded by research grants from the Ministry of Health and Welfare of Japan (H10-12, No. 063, Research on Health Services, Health Sciences Research Grants and H13, No. 010, Medical Frontier Strategy Research, Health Sciences Research Grants), the Ministry of Health, Labor, and Welfare of Japan (H14-15, No. 010, Clinical Research for EvidenceBased Medicine, Health, and Labor Sciences Research Grants), and the Japan Arteriosclerosis Prevention Fund 2004.

We thank Toshimi Yoshida of the Department of Health Science, Shiga University of Medical Science, for her excellent clerical support during this research.

Investigators and members of the research group are listed in the appendix of Okamura et al. ${ }^{11}$

\section{Disclosure}

None of the authors have any conflicts of interest related to this manuscript.

\section{References}

1. Bhatt DL, Steg PG, Ohman EM, et al. International prevalence, recognition, and treatment of cardiovascular risk factors in outpatients with atherothrombosis. JAMA. 2006;295:180-189.
2. Meigs JB, D'Agostino RBS, Wilson PW, Cupples LA, Nathan DM, Singer DE. Risk variable clustering in the insulin resistance syndrome. The Framingham Offspring Study. Diabetes. 1997;46:1594-1600.

3. Executive Summary of the Third Report of the National Cholesterol Education Program (NCEP) Expert Panel on Detection, Evaluation, and Treatment of High Blood Cholesterol in Adults (Adult Treatment Panel III). JAMA. 2001;285:2486-2497.

4. ParkYW, Zhu S, Palaniappan L, Heshka S, Carnethon MR, Heymsfield SB. The metabolic syndrome: prevalence and associated risk factor findings in the US population from the Third National Health and Nutrition Examination Survey, 1988-1994. Arch Intern Med. 2003;163:427-436.

5. Ferrie JE, Shipley MJ, Cappuccio FP, et al. A prospective study of change in sleep duration; associations with mortality in the Whitehall II cohort. Sleep. 2007;30:1659-1566.

6. Eguchi K, Yacoub M, Jhalani J, Gerin W, Schwartz JE, Pickering TG. Short sleep duration as an independent predictor of cardiovascular events in Japanese patients with hypertension. Arch Intern Med. 2008; 168:2225-2231.

7. Hall MH, Muldoon MF, Jeuning JR, Buysse DJ, Flory JD, Manuck SB. Self-reported sleep duration is associated with the metabolic syndrome in midlife adults. Sleep. 2008;31:635-643.

8. Nigam A, Bourassa MG, Fortier A, Guertin MC, Tardif JC. The metabolic syndrome and its components and the longterm risk of death in patients with coronary heart disease. Am Heart J. 2006;151:514-521.

9. Tillin T, Forouhi NG, McKeigue PM, Chaturvedi N. The role of diabetes and components of the metabolic syndrome in stroke and coronary heart disease mortality in UK white and African-Caribbean populations. Diabetes Care. 2006;29:2127-2129.

10. Kadota A, Hozawa A, Okamura T, et al. Relationship between metabolic risk factor clustering and cardiovascular mortality stratified by high blood glucose and obesity. Diabetes Care. 2007;30:1533-1538.

11. Okamura T, Tanaka T, Babazono A, et al. The high-risk and population strategy for occupational health promotion (HIPOP-OHP) study: study design and cardiovascular risk factors at the baseline survey. $J$ Hum Hypertens. 2004;18:475-485.

12. Okamura T, Tanaka T, Yoshita K, et al. Specific alcoholic beverage and blood pressure in a middle-aged Japanese population: the high-risk and population strategy for occupational health promotion (HIPOP-OHP) study. J Hum Hypertens. 2004;18:9-16.

13. Naito M, Nakayama T, Okamura T, et al. Effect of a 4-year workplacebased physical activity intervention program on the blood lipid profiles of participating employees: the high-risk and population strategy for occupational health promotion (HIPOP-OHP) study. Atherosclerosis. 2008; 197:784-790.

14. Tamura U, Tanaka T, Okamura T, et al. Changes in weight, cardiovascular risk factors and estimated risk for coronary heart disease following smoking cessation in Japanese male workers: HIPOP-OHP Study. J Atheroscler Throm. 2010;17:12-20.

15. Nakamura M, Sato S, Shimamoto T. Improvement in Japanese clinical laboratory measurements of total cholesterol and HDL-cholesterol by the US Cholesterol Reference Method Laboratory Network. J Atheroscler Thromb. 2003;10:145-153.

16. Craig CL, Marshall AL, Sjostrom M, et al. The International Physical Activity Questionnaire (IPAQ): a comprehensive reliability and validity study in twelve countries. Med Sci Sports Exerc. 2003;35: 1381-1395.

17. Alberti KG, Zimmet P, Shaw J. IDF Epidemiology Task Force Consensus Group. The metabolic syndrome - a new worldwide definition. Lancet. 2005;366:1059-1062.

18. International Diabetes Federation. The IDF consensus worldwide definition of the metabolic syndrome. http://www.idf.org/webdata/ docs/MetS_def_update2006.pdf. Accessed February 22, 2011.

19. Santos AC, Ebrahim S, Barros H. Alcohol intake, smoking, sleep hours, physical activity and the metabolic syndrome. Prev Med. 2007;44:328-334.

20. Choi KM, Lee JS, Park HS, Baik SH, Choi DS, Kim SM. Relationship between sleep duration and the metabolic syndrome: Korean National Health and Nutrition Survey 2001. Int J Obes (Lond). 2008;32: 1091-1097. 
21. Bjorvatn B, Sagen IM, Øyane N, et al. The association between sleep duration, body mass index and metabolic syndrome in the Hordaland Health Study. J Sleep Res. 2007;16:66-76.

22. Watanabe M, Kikuchi H, Tanaka K, Takahashi M. Association of short sleep duration with weight gain and obesity at 1-year follow-up: a large-scale prospective study. Sleep. 2010;33:161-167.

23. Vgontzas AN, Lin HM, Papaliaga M, et al. Short sleep duration and obesity: the role of emotional stress and sleep disturbances. Int $J$ Obes(Lond). 2008;32:801-809.

24. Taheri S, Lin L, Austin D, Young T, Mignot E. Short duration is associated with reduced leptin, elevated ghrelin, and increased body mass index. PLoS Med. 2004;1:e62.

25. Spiegel K, Tasali E, Penev P, Van Cauter E. Brief communication: sleep curtailment in healthy young men is associated with decreased leptin levels, elevated ghrelin levels, and increased hunger and appetite. Ann Intern Med. 2004;141:846-850.

26. Sivak M. Sleeping more as a way to lose weight. Obes Rev. 2006; 7 : 295-296.

27. Patel SR, Malhotra A, White DP, Gottlieb DJ, Hu FB. Association between reduced sleep and weight gain in women. Am J Epidemiol. 2006;164:947-954.

28. Von Kries R, Toschke AM, Wurmser H, Sauerwald T, Koletzko B. Reduced risk for overweight and obesity in 5- and 6-y-old children by duration of sleep - a cross-sectional study. Int J Obes Relat Metab Disord. 2002;26:710-716.

29. Reilly JJ, Armstrong J, Dorosty AR, et al. Early life risk factors for obesity in childhood: cohort study. BMJ. 2005;330:1357.

30. Agras WS, Hammer LD, McNicholas F, Kraemer HC. Risk factors for childhood overweight: a prospective study from birth to 9.5 years. J Pediatr. 2004;145:20-25.
31. Chaput JP, Despres JP, Bouchard C, Tremblay A. Short sleep duration is associated with reduced leptin levels and increased adiposity: results from the Quebec Family Study. Obesity. 2007;15:253-261.

32. Patel SR, Malhotra A, Gottlieb DJ, White DP, Hu FB. Correlates of long sleep duration. Sleep. 2006;29:881-889.

33. Gottlieb DJ, Punjab NM, Newman AB, et al. Association of sleep time with diabetes mellitus and impaired glucose tolerance. Arch Intern Med. 2005;165:863-868.

34. Yaggi HK, Araujo AB, Mckinlay JB. Sleep duration as a risk factor for the development of type 2 diabetes. Diabetes Care. 2006;29:657-661.

35. Chaput JP, Despres JP, Bouchard C, Astrup A, Tremblay A. Sleep duration as a risk factor for the development of type 2 diabetes or impaired glucose tolerance: analyses of the Quebec Family Study. Sleep Med. 2009;10:919-924.

36. Van den Berg JF, Miedema HM, Tulen JH, et al. Long sleep duration is associated with serum cholesterol in the elderly: the Rotterdam Study. Psychosom Med. 2008;70:1005-1011.

37. Kaneita Y, Uchiyama M, Yoshiike N, Ohida T. Associations of usual sleep duration with serum lipid and lipoprotein levels. Sleep. 2008;31:645-652.

38. Cappuccio FP, Strange S, Kandala NB, et al. Gender-specific associations of short sleep duration with prevalent and incident hypertension: the Whitehall II Study. Hypertension. 2007;50:693-700.

39. Gangwisch JE, Heymsfield SB, Boden-Albala B, et al. Short sleep duration as a risk factor for hypertension: analyses of the first National Health and Nutrition Examination Survey. Hypertension. 2006;47:833-839.

40. Nakamura Y, Turin TC, Kita Y, et al. The associations of obesity measures with the metabolic risk factors in a community-based population in Japan. Circ J. 2007;71:776-781.

\section{Publish your work in this journal}

Diabetes, Metabolic Syndrome and Obesity: Targets and Therapy is an international, peer-reviewed open-access journal committed to the rapid publication of the latest laboratory and clinical findings in the fields of diabetes, metabolic syndrome and obesity research. Original research, review, case reports, hypothesis formation, expert opinion and commentaries are all considered for publication. The manuscript management system is completely online and includes a very quick and fair peer-review system, which is all easy to use. Visit http://www.dovepress.com/testimonials.php to read real quotes from published authors. 